\title{
El estatuto de la ética aplicada. Hermenéutica crítica de las actividades humanas
}

\author{
ADELA CORTINA \\ Universidad de Valencia
}

Durante algún tiempo el problema de la fundamentación de lo moral atrajo la atención de los éticos. Hoy en día, el «giro aplicado» sufrido por la filosofía afecta en primer término a la ética y le pide orientaciones, aunque mediatas como es propio de la filosofía, para organizar la vida en las distintas esferas de la vida social. Este cambio exige ante todo aclarar cuál debe ser el proceder de la ética aplicada (deductivo, inductivo, hermenéutico), si existen principios comunes a sus distintos ámbitos o constituyen reinos de taifas, cuáles son los principios, hábitos y valores que cada esfera exige para moralizarse, en el sentido de Orlega, qué métodos son adecuados para la toma de decisiones.

Estas exigencias están ya en la calle y piden interdisciplinariedad. No intentar responder a ellas es reconocer, frente a la pretensión originaria, que a la filosofía no le importa la vida, no le importa si los seres humanos viven bien.

\section{PLANTEAMIENTO DEL PROBLEMA}

\section{El giro aplicado de la ética}

La historia de la filosofía es, de algún modo, la historia de sus giros. En pleno siglo $\mathrm{XX}$ hemos sufrido al menos cuatro: el giro lingüístico, el hermenéutico, el pragmático y, por último, el giro aplicado. Frente a la idea aristotélica de que un saber es más digno cuanto más inútil, la filosofía de nuestros días trata de resultar útil a la sociedad y a las personas, tal vez por gozar entre ellas de cierta legitimidad.

Evidentemente, si esto puede decirse de la filosofía como tal, es la filosofía práctica, y muy concretamente la ética o filosofía moral, la que pone mayor empeño en hacerse aplicada, en orientar la acción y las decisiones de los seres humanos. Hace algún tiempo los éticos empleaban buena parte de su esfuerzo en intentar encontrar un fundamento para lo moral; hoy, sin embargo, la ética aplicada en sus diferentes vertientes (bioética, ética de la economía y de la empresa, genética, ética de la información, ética ecológica, ética de las profesiones) ${ }^{1}$ atrae la atención, no sólo de los éticos, sino de los expertos en

'A. Etchegoyen habla de La Valse des Ethiques, Paris, F. Bourin, 1991. 
los campos que acabo de mencionar y también de la opinión pública: la ética aplicada está de moda. ¿A qué se debe?

Tal vez al hecho de que, como afirma Lipovetsky, los individuos toman cada vez más conciencia de sus derechos y exigen a las instituciones que los respeten, que se «moralicen» ${ }^{2}$. Tal vez-diria yo- al hecho de que las personas nos vayamos percatando de que somos «interlocutores válidos» en las cuestiones que nos afectan y deseamos ser tenidos realmente en cuenta en los distintos ámbitos de la vida social ${ }^{3}$. En cualquier caso es claro que la ética individual hoy nos parece insuficiente para resolver los problemas de nuestra convivencia, y que también el derecho ha mostrado sus límites: las éticas aplicadas a los distintos campos devienen una necesidad social. Con lo cual no ha disminuido el número de problemas filosóficos, sino simplemente han pasado al primer plano cuestiones que hasta el momento quedaban relegadas.

En efecto, resulta evidente que la ética aplicada no puede ser una moral más de las que forman parte de la vida cotidiana, precisamente por su carácter de «ética»; sin embargo, de igual modo que las morales de la vida cotidiana, pretende orientar la acción, incluso en las tomas concretas de decisión. Por ejemplo, a través de comités asistenciales en centros hospitalarios ${ }^{4}$, o a través de auditorias éticas que prestan sus servicios a las empresas ${ }^{5}$. No se trata, pues, de un tipo de reflexión que queda en las aulas y en los seminarios, sino que pretende orientar la acción en la vida cotidiana. Esta situación plantea un buen número de problemas: ise trata de un saber filosófico o son más bien los expertos de cada campo social los llamados a construir la ética aplicada?, ¿cómo se articula y qué tipo de método es el que le corresponde?, ¿cuentan las distintas éticas aplicadas con algún principio común a todas ellas, o son independientes entre sí?

Para intentar responder a estas preguntas trataremos de aclarar en principio algunas cuestiones terminológicas para pasar después a considerar cuál es el estatuto propio de la ética aplicada. Con tal fin comentaré tres propuestas metodológicas que ya funcionan, pero que considero insuficientes (casuística 1994).

' G. Lipovetsky, Le crepuscule du devoir, PUF, Paris, 1992 (trad, cast. Barcelona, Anagrama,

${ }^{3}$ A. Cortina, Etica aplicada y democracia radical, Tecnos, Madrid, 1993, sobre todo parte III: «Los retos de la ética aplicada».

" Para los comités de ética en sus diferentes modalidades ver Cranford/Doudera, «The emergence of institutional ethics commitees», en Institutional Ethics Commitees and Health Care Decision Making, Ann Arbor, Health Administration Press, 1984; R. M. Vcatch, The Ethics of Institutional Ethics Commitees, 1984; M. Julia Bertomeu, «La ética en los comites de ética» (1988), pp. 81-83; Francisco Abel, "Comites de bioética; necesidad, estructura y funcionamiento", en Labor Hos" pitalaria, núm. 229; M. "Pilar Náñez-Cubero, "Comités Nacionales de Biêtica», Labor Hospitalaria, 229. pp. 147-160; Miguel Sắnchez, "Los comités de bioética y los derechos de los enfermos», Actas del III Congreso de Servicios de Atención al Ustario de la Sanidad, Málaga, Talleres Gráficos Salcedo, S. A., 1990, pp. 35-47; Mignel Ángel Broggi Trías, "Conitěs de ética hospitalarios», en Medicina Clínica, núm. 96, 1991; O. M. Bakke, X. Carné, F. García Alonso, Ensayos Clínicos con Medicamentos, Barcelona, Coyma, 1994; Adela Cortina, «Comités de Ética», en Enciclopedia Iberoamericana de Filosofía, en prensa.

s Cortina, J. Conill, A. Domingo, D. García Marzá, Ética de la empresa, Trotta, Madrid, 1994 , cap. 6. 
1, casuística 2, aplicación de la ética del discurso, tal como K. O. Apel la diseña ${ }^{6}$ ), y presentaré la mía como hermenéutica crítica de las actividades sociales.

\section{Moral y Ética aplicada?}

Ciertamente, "moral» y «ética" son dos expresiones que no se distinguen ni por su significado etimológico ni por el uso que de ellas se hace en la vida cotidiana. Sin embargo, desde un punto de vista filosófico conviene distinguir entre la moral y la ética o filosofía moral, porque se refieren a dos niveles de reflexión y lenguaje: el nivel de la vida cotidiana, en que los hombres viven desde antiguo con referentes morales, y el nivel de la filosofía moral, que reflexiona sobre la moral vivida en la vida cotidiana ${ }^{8}$.

Entre las tareas de la ética cuentan las de intentar dilucidar en qué consiste lo moral, tratar de fundamentarlo, es decir, inquirir las razones para que haya moral o bien reconocer que no las hay, e intentar aplicar los principios éticos descubiertos mediante la fundamentación a los distintos ámbitos de la vida cotidiana.

Con la enumeración de estas tres tareas se echa de ver que las éticas, a diferencia de las morales, no llevan «apellidos» propios de la vida cotidiana (moral católica, musulmana, calvinista), sino filosóficos (éticas kantianas, comunitarias, utilitaristas), porque intentan reflexionar sobre el fenómeno de la moralidad en su conjunto, utilizando para ello los métodos y el lenguaje propios de las tradiciones filosóficas.

Sin duda existe una estrechísima conexión entre ambos niveles, porque el filósofo no puede sino reflexionar sobre la moral vivida, y porque de algún modo sus reflexiones pueden influir de nuevo en cl quehacer moral cotidiano. Pero la distinción entre moral y filosofía moral se hace necesaria, a pesar de todo, porque la moral forma parte del vivir de los hombres, sean o no expertos en ética, mientras que esta última requiere un aprendizaje y un lenguaje especializados.

Sólo desde este tipo cspecífico de reflexión puede la ética aventurar orientaciones para la vida cotidiana y por eso su parte «aplicada» no puede prescribir de forma inmediata las actuaciones en los casos concretos, sino únicamente orientar de forma mediata, ofreciendo un marco reflexivo para la toma concreta de decisiones. Sin embargo, en esta tarea no pueden actuar los éticos en solitario, sino que tienen que desarrollarla cooperativamente con los expertos de cada

\footnotetext{
${ }^{5}$ Por su parte, Jürgen Habermas considera que la ética no tienc por tarca aplicar el principio ético, sino sólo fundamentar la moral.

'A. Cortina, Ética minima, Tecnos, Madrid, 1986, parte I; Ética sin moral, Tecnos, Madrid, 1990, cap. 1.

J. L. Aranguren, Ética, Revista de Occidente, Madrid, 1958.
} 
campo (médicos, enfermeras, empresarios, periodistas, etc.). Como veremos al tratar sobre el problema del método, la ética aplicada es necesariamente interdisciplinar.

\section{TRES MODELOS POSIBLES, PERO INSUFICIENTES}

\section{Casuistica 1. El ideal deductivo}

\subsection{La expresión misma «ética aplicada» («applied ethics», «Anwendungsethik»)} resulta confundente. Provoca la sensación de que la ética cuenta con un conjunto de principios claros y que sólo se trata de aplicarlos a los casos concretos de una manera prudencial. La ética aplicada funcionaría entonces de un modo deductivo, ya que partiría de unos axiomas desde los cuales extraería conclusiones para las situaciones concretas. Este modo de proceder coincide con el modelo tradicional de aplicación de la ética, al que John D. Arras ha dado el nombre de «casuística 1 ».

La casuística 1 consiste en el karte de aplicar cualquier tipo de principios morales que se tengan a mano a los casos concretos»" ya que considera los casos concretos como una particularización de los principios generales ${ }^{10}$. Este modelo de aplicación destaca muy especialmente el valor de la teoría, de la deducción y de la búsqueda de certeza moral. Históricamente, tiene su origen en la filosofía de Platón y Aristóteles, y continúa presente en las de Tomás de Aquino o Spinoza. Su figura es la propia del silogismo práctico, que cuenta con dos niveles: un momento universal, constituido por principios universales y axiomáticos, y un momento particular en el que entran en juego las razones concretas, y en el que resulta indispensable la prudencia como recta ratio agibilium.

1.2. A mi juicio, la casuística 1 resulta inviable hoy en día como método de la ética aplicada, sobre todo por dos razones:

1) Para recurrir a un modelo de aplicación semejante sería necesario contar con principios materiales universales, cosa que ninguna ética puede hoy ofrecer, porque los principios éticos, o bien son universales y entonces son formales o procedimentales, o bien son materiales, pero entonces pierden universalidad.

Los principios rawlsianos de la justicia, por ejemplo, son sustantivos pero, como el propio Rawls reconoce, no pueden pretender validez en principio más que para las sociedades occidentales con democracia liberal ${ }^{11}$. Precisamente porque se han descubierto a través del método del «equilibrio reflexivon entre

' John D. Arras, «Common Law Morality»; Hastings Center Report, 1990, 20-35.

"Diego Gracia, Procedimientos de decisión en ética clinica, Eudema, Madrid, 1991, 98-101.

"J. Rawls, Political Liberalism, Columbia University Press, 1993. 
los «juicios meditados» sobre la justicia de las sociedades occidentales con democracia liberal, la posición original y los propios principios. Por su parte, el principio de la ética discursiva pretende valer universalmente, pero es puramente procedimental ${ }^{12}$.

2) La actual ética aplicada ha nacido más de las exigencias «republicanas» de las distintas esferas de la vida social (medicina, empresa, genética, medios de comunicación, ecología, etc.), que de la «monarquía» de unos principios con contenido que quieren imponerse a la realidad social. Las situaciones concretas no son mera particularización de principios universales, sino lugar de descubrimiento de los principios y los valores morales propios del ámbito social correspondiente.

\section{Casuística 2. Una propuesta inductiva.}

2.1. La casuística 2 se caracteriza también, según Arras, por utilizar un procedimiento inductivo, del tipo del que proponen Albert R. Jonsen y Stephehn Toulmin en su libro The Abuse of Casuistry ${ }^{13}$. Jonsen y Toulmin proponen sustituir los principios o axiomas iniciales por máximas, que son critcrios sabios y prudentes de actuación práctica, en los que coinciden todo el mundo, la mayoria o los especialistas. En definitiva, las máximas son el resultado de la sabiduria práctica de los hombres y las culturas, y resultan una ayuda más valiosa para tomar decisiones que los presuntos principios de la razón pura. El principal problema no es, pues, el del casuismo (resolver casos concretos), sino el del principialismo (descubrir principios universales).

La casuistica 2 es entonces un método de aplicación de carácter retórico y práctico, entendiendo por retórica el arte de realizar juicios probables sobre situaciones individuales y concretas. En este tipo de juicios, que alcanza pro* babilidad y no certeza, la solución de los conflictos no se alcanza por la aplicación de axiomas formulados a priori, sino por el criterio convergente de todos los hombres, o al menos de los más prudentes y sabios, expresados en forma de máximas de actuación ${ }^{14}$.

Quienes defienden la casuística 2 como modo de proceder en bioćtica no pretenden sino asumir explícitamente el método para llegar a decisiones racionales que la bioćtica ya ha emprendido. Es decir, que no tratan sino de reflexionar acerca de sus propias experiencias y formularlas en forma de método, porque se han percatado de que, aunque les resulte imposible llegar a acuerdos con otros especialistas en el terreno de los principios éticos, la necesidad de

' Karl-Otto Apel, La transfornación de la filosofia, Madrid, Taurus, 1985, II, pp. 380 y 381 ; Jürgen Habermas, Conciencia moral y acción comunicativa, Barcelona, Península, p. 117, Faktizität und Geltung, Frankfurt, Suhrkamp, 1992, pp. 138 y 139.

Albert R. Johnsen/Stephen Toulmin, The Abuse of Casuistry. A History of Moral Reasonimg Berkeley, Los Ángeles, Londres, University of Chicago Press, 1988.

1. D. Gracia, Procedimientos de decisión en ética clinica, 97 y 98. 
tomar decisiones conjuntas ha revelado que pueden ponerse de acuerdo en ciertas máximas para orientarse en los casos concretos. Si las máximas, obtenidas por convergencia, son suficientes para la toma racional de decisión, ¿qué otra cosa necesita la bioética más que extraer la racionalidad de estas experiencias y plasmarla metódicamente? Éste sería el caso de los «principios de la bioética», que no son sino principios de alcance medio, acordados por gentes prudentes. ${ }^{13}$

¿No sería posible - nos preguntamos- descubrir en los restantes campos de la ética aplicada principios propios de cada uno de ellos? ¿No sería más útil tratar de detectar en cada uno las máximas a las que han ido llegando los más sabios y prudentes?

La ventaja de la casuística 2 es que recoge los pasos de un método que ya funciona con excelentes resultados. De hecho la bioética, con todas sus insuficiencias, es el tipo de ética aplicada sobre el que existe mayor acuerdo a nivel internacional: los cuatro principios y las normas de Helsinki son orientaciones ya indiscutibles en la aplicación a la praxis médica.

2.2. Sin embargo, la casuística 2 muestra a mi juicio al menos dos insuficiencias:

1) No es cierto que no exista ningún principio ético universal, que es en realidad el que sirve de marco legitimador a los tres principios de la bioética y a cuantas máximas y valores descubramos en los distintos ámbitos de la ética aplicada. Sólo que este principio no es material, como querría la casuística 1 , sino procedimental; ni procede tampoco de una razón «pura», como desearia un kantismo estricto, sino de una razón «impura», históricamente generada ${ }^{16}$. Este principio constituye el trasfondo ético de una cultura social y política democrática y pluralista y se modula de distinta forma en los distintos ámbitos de la vida social ${ }^{17}$.

Es imposible exponer aquí todo el procedimiento de búsqueda de ese principio, hecho por el cual me limito a extraer las conclusiones de to tratado extensamente en otros lugares ${ }^{18}$ : ese principio no es el utilitarista, que es utilizable en las tomas concretas de decisión, no en el marco de la ética aplicada. El principio ético que está verdaderamente en el trasfondo es un principio procedimental, que expresa la conciencia moral propia del nivel postconven-

"The Belmont Report: Ethical Principles and Guidelines for the Protection of Human Subjelcs of Research, Bethesda, Md.: The National Commission for the Protection of Human Subjects of Biomedical and Behavioral Research, 1978 (trad. en esp. en Ensayos Clinicos en España (1982-1988). Ministerio de Sanidad y Consumo, Monografías Técnicas, núm. 17 (1990), Anexo 4; T. L. Bcauchamp/J. F. Childres, Principles of Biomedical Ethics, Oxford, U. P., 1979; H. T. Engelhardt, The Foundations of Bioethics, Oxford U. P., 1986 (hay trad. cast. en Barcelona, Paidos, 1995); Diego Gracia, Fundamentos de Bioética, Madrid, Eudema, 1988; Primum non nocere, Madrid, Instituto de España, Real Academia Nacional de Medicina, 1990.

${ }^{16}$ Jesús Conill, El enigma del animal fantástico, Tecnos, Madrid, 1991.

"Adela Cortina, Ética aplicada y democracia radical, cap. 10.

A Cortina, Ética minima; Etica sin moral, Ética aplicada y democracia radical; Etica de la sociedad civil, Madrid, Anaya/Alauda, 1994. 
cional de Kohlberg en el desarrollo de la conciencia moral social. Se trata del principio sacado a la luz por la ćtica del discurso de $\mathrm{K}$. O. Apel y J. Habermas, si bien el modo de aplicarlo que Apel propone por el momento resulta, a mi juicio, insatisfactorio. Por eso comentaré en principio la propuesta de Apel y cuáles creo que son sus insuficiencias, y a continuación mi propia propuesta.

2) La existencia de este principio se echa de ver incluso en el caso de la bioética. Si la bioética funcionara en realidad tal como dice la casuística 2 , llegaría a unos principios que captamos por intuición, entre los que resultaría imposible tomar decisiones racionales. Ni siquiera podríamos establecer entre ellos un orden lexicográfico, como el que Rawls establece entre los principios de la justicia ${ }^{19}$. ¿Qué hacer cuando se plantea un problema moral, es decir, cuando las máximas entran entre sí en conflicto?

No es verdad que no haya de hecho un principio universal, común a los distintos ámbitos, sólo que no se descubre por una suerte de intuición, ni tampoco a partir de él se extraen conclusiones para los casos concretos de forma deductiva.

\section{Más allá de la deducción y la inducción: aplicación del principio procedimental de la ética discursiva}

3.1. La ética del discurso, que K. O. Apel y J. Habermas empezaron a pergeñar a partir de los años 70 , ofrece un fundamento de lo moral que transforma dialógicamente el principio formal kantiano de la autonomia de la voluntad en el principio procedimental de la ética discursiva ${ }^{20}$. Tal principio puede formularse del siguiente modo:

«Todos los seres capaces de comunicación lingüística deben ser reconocidos como personas, puesto que en todas sus acciones y expresiones son interlocutores virtuales, y la justificación ilimitada del pensamiento no puede renunciar a ningún interlocutor y a ninguna de sus aportaciones virtuales a la discusion.» ${ }^{21}$

19 Aceptando una fundamentación de la bioetica, aunque de corte zubiriano, D. Gracia introduce un orden lexicográfico entre los cuatro principios de la bioética en Procedimientos de decisión en ética clinica, cap. 9.

233 Para la fundamentación y aplicaciớn de la ética del discurso ver Karl-Otto Apel, La transformación de la filosofia, II, pp. 341 y ss.; Diskars und Verantwortung, Suhrkamp, Frankfurt, 1988; Kafl-Otto Apel/Adela Cortina/Julio De Zan/Dorando Michelini (eds.), Etica comunicativa y democracia: Jürgen Habermas, Conciencia moral y acción comunicativa; Erläutenungen zur Diskursethik, Suhrkamp, 1992; Adela Cortina, Ética mínima; Ética sin moral; Élica aplicada y democracia radicul; Javier Muguerza, Desde la perplejidad, Madrid, F. C. E., 1991; Domingo García Marzá, Ética de la Justicia, Madrid, Tecnos, 1992; Karl-Otto Apel/Matthias Kettner (eds.), Zur Anwendung der Diskursethik in Politik, Recht und Wissenschaft, Suhrkamp, Frankfurt, 1992; Guillermo Hoyos, Derechos hamanos, etica y moral, Santa Fe de Bogotả, Fundación Sical, 1995.

${ }^{1}$ K. O. Apel, La iranformación de la filosofia, II, pp. 380 y 381 . 
En este texto Apel reconstruye desde una perspectiva dialógica dos conceptos ya clásicos en la ética occidental: los conceptos de persona y de igualdad. La persona se nos presenta ahora como un interlocutor válido, que como tal debe ser reconocido por cuantos pertenecen a la comunidad de hablantes; la idea de igualdad se torna ahora comunicativa, en la medida en que ninguna persona, ningún interlocutor válido puede ser excluido a prion de la argumentación cuando ésta versa sobre normas que le afectan. $O$, por decirlo en palabras de Habermas:

«Sólo son válidas aquellas normas de acción con las que podrían estar de acuerdo todos los posibles afectados como participantes en un discurso práctico» ${ }^{22}$.

En afirmar que la ética tiene esta misión de fundamentar la dimensión normativa de lo moral coinciden Apel y Habermas. Pero sólo Apel distingue dos partes en la ética: la parte A, que se ocupa de la fundamentación racional de la corrección de normas, y la parte $\mathrm{B}$, preocupada por diseñar el marco racional de principios que permiten aplicar en la vida cotidiana el principio descubierto en la parte A. ¿Qué es lo específico de la parte B?

Según Apel, así como la parte $\mathrm{A}$ de la ética se orienta por la idea de fundamentación, la parte $B$ se orienta por la de responsabilidad. Porque una cosa es descubrir el principio ético ideal; otra, intentar aplicarlo a los contextos concretos, en los que la aplicación siempre viene condicionada por las consecuencias y por las situaciones. Si la ética del discurso - piensa Apcl- fuera totalmente kantiana tendría que exigir que su principio ético se cumpliera en cualquier tiempo y lugar. En tal caso el principio se formularía del modo que A. M. Pieper sugiere: «iObra (siempre) como si fueras miembro de una comunidad ideal de comunicación!» ${ }^{23}$.

Sin embargo, exigir moralmente que siempre se actúe según el principio de la ética discursiva es para Apel y concuerdo con él una irresponsabilidad. Por eso conviene atender el consejo de Weber y optar por una ética de la responsabilidad, pero añadiría yo por una ética de la responsabilidad convencida o de la convicción responsable, porque no se trata con ella de renunciar a las convicciones, sino todo lo contrario: se trata de ser responsable de las consecuencias que pueden acercarnos a una meta de cuyo valor estamos con-

${ }^{22}$ J. Habermas, op. cit, p. 117. En Faktlizität und Geltung se niega Habcrmas a denominar a este principio eprincipio de la ética del discurso» y le denomina «principio del discurso», alegando que la justificación de normas en general exige seguir un principio normativo, moralmente neutral, que expresa el sentido de la imparcialidad, mientras que la moral está ligada a un tipo específico de normas. En cualquier caso, para lo que aquí nos importa, sigue siendo válido que, desde el punto de vista de una conciencia moral crítica, situada en el nivel postconvencional, son válidas las normas con las que podrían estar de acuerdo todos los afectados por ellas como participantes en un discurso práctico, porque satisfacen intereses universalizables.

${ }^{3}$ Citado por Apel, en «Diskursethik vor der Problematik von Recht und Politik», en K.-O. Apel/M. Kettner (Hrgs.), Zur Anwendung der Diskursethik in Politik, Recht und Wissenschaft, p. 36. 
vencidos, o bien alejarnos de ella. En el caso de la ética discursiva esto significa que la aplicación del principio tiene que venir mediada por el uso de la racionalidad estratégica, siempre que se pretendan con ello dos metas: 1) la conservación del sujeto hablante y de cuantos de él dependen; 2) poner las bases materiales y culturales para que algún día sea posible actuar comunicativamente sin que con ello peligre la conservación propia y ajena. El nuevo imperativo ético dialógico diría así: «jObra siempre de tal modo que tu acción vaya encaminada a sentar las bases (en la medida de lo posible) de una comunidad ideal de comunicación!»

Ciertamente, la preocupación por diseñar un marco de mediación del principio ético por la racionalidad cstratégica dota a la ética discursiva de un «realismon que la hace aplicable en ámbitos como el político, el económico o el mundo de la violencia ${ }^{24}$.

3.2. Sin embargo, frente al modelo de aplicación propuesto por Apel quisiera recordar al menos tres cosas:

1) El necesario uso de estratcgias es un factor importante en determinados ámbitos de la ética aplicada, como son el de la empresa o la política, pero no tanto en otros, como el de la bioética.

2) En aquellos campos en los que es un factor importante, no es el único. Que la empresa, por ejemplo, pueda y deba hacer uso de estrategias todavía no dice nada sobre cuáles son los valores por los que la empresa ha de orientarse (corresponsabilidad, calidad, equidad, etc.). Es decir, no dice nada sobre cómo en ese ámbito social el reconocimiento de los afectados como interlocutores válidos da lugar a unos valores específicos de ese mundo.

3) La distinción de niveles (A y B) da la sensación de que descubrimos un principio y tenemos que diseñar un marco para aplicarlo a los casos concretos, cuando en realidad se trata de descubrirlo en los distintos ámbitos y averiguar cómo debe modularse en cada uno de ellos.

\section{PROPUESTA DE UN NUEVO MODELO DE ÉTICA APLICADA COMO HERMENÉUTICA CRÍTICA ${ }^{25}$}

\section{El marco deontológico (El momento «kantiano»)}

1) La estructura de la ética aplicada, tal como aquí la proponemos, no es deductiva ni inductiva, sino que goza de la circularidad propia de una her-

${ }^{24} \mathrm{La}$ idea de que es necesario aplicar responsablemente el principio en cualquier contexto, pero especialmente en situaciones de violencia, es perfectamente comprendida por un buen número de interlocutores, sobre todo en América Latina. Ver Jon Sobrino, «Apuntes para una espiritualidad en tiempos de violencia», en Iglesia, Sociedad y Reconciliación, Desclée de Brouwer, 1993, pp. 113-139; Adela Cortina, Etica aplicada y democracia radical pp. 183-192.

${ }^{25}$ A. Cortina, Ética aplicada y democracia radical, III. 
menéutica crítica, ya que es en los distintos ámbitos de la vida social donde detectamos como trasfondo un principio ético (el del reconocimiento de cada persona como interlocutor válido) que se modula de forma distinta según el ámbito en que nos encontremos. No sc trata, pues, con la «aplicación» de aplicar principios generales a casos concretos, ni tampoco de inducir únicamente máximas desde las decisiones concretas, sino de descubrir en los distintos ámbitos la peculiar modulación del principio comin. Cada campo tiene una innegable especificidad y por eso hay una melodía común a ellos, pero expresada en muy diferentes versiones. Atender tanto a la melodía como a las versiones es imprescidible y eso es lo que nos obliga a practicar la interdisciplinariedad.

Pasaron los tiempos «platónicos», en los que parecía que el ético descubría unos principios y después los aplicaba sin matizaciones urbi et orbe. Más bien hoy nos enseña la realidad a ser muy modestos y a buscar junto con los espeialistas de cada campo qué principios de alcance medio y qué valores se perfilan n él y cómo deben aplicarse en los distintos contextos. La interdisciplinaridad no es, entonces, una moda, sino una urgencia.

2) El principio procedimental de la ética del discurso es únicamente una orientación de trasfondo, to cual significa que necesitamos contar con otras tradiciones éticas para componer el modelo de aplicación.

Sin duda las distintas tradiciones se han ido mostrando con el tiempo como unilaterales, de sucrte que, incluso al nivel de la fundamentación, es necesaria una complementariedad entre ellas. Las dicotomías éticas clásicas -éticas teleológicas/deontológicas, de la convicción/de la responsabilidad, procedimentalistas/sustancialistas - han de ser superadas en un «tercero» que constituya la verdad de ambas ${ }^{26}$. Sin embargo, lo que es hoy patente ya en cualquier intento de fundamentar lo moral, resulta diáfano en la ética aplicada: un solo modelo de ética es impotente para orientar las decisiones de los mundos político y económico, médico, ecológico o, simplemente, la convivencia ciudadana.

Por eso nos vemos obligados a tener en cuenta los diferentes modelos en el momento oportuno, aunque el elemento coordinador será la ética del discurso, porque hunde sus raíces en la acción comunicativa y en la subsiguiente argumentación, que constituyen el medio de coordinación aunque no la sustancia de las restantes actividades humanas. La idea de sujeto como interlocutor válido configura el trasfondo «melódico» común a todas las esferas, ya que en todas ellas es el afectado, en último término, quien está legitimado para exponer sus intereses, y sólo deben considerarse legítimas aquellas normas que satisfagan los intcreses universalizables. Pero además la consideración de ese sujeto como interlocutor válido genera una scric de cxigencias, que se entenderán al modo de Dworkin «todos merecen igual consideración y respeto» o de otras formas.

\footnotetext{
2t Ética sin moral, cap. 2.
} 


\section{2. Ética de las actividades sociales (EI momento maristotélico»)}

2.0. Ahora bien, icómo descubrir en cada campo de la ética aplicada las máximas y valores que en ese ámbito son exigidas por el reconocimiento de cada persona como interlocutor válido? Diversas respuestas son posibles pero, en principio, todas coincidirían en reconocer que no nos las habemos con éticas individuales. Precisamente una de las razones del nacimiento de la ética aplicada es el descubrimiento de que la ética individual es insuficiente, porque la buena voluntad personal puede, sin embargo, tener malas consecuencias para la colectividad. La época de la buena intención, la época «moralista» según G. Lipovetsky, da paso a éticas aplicadas en que es más importante la inteligencia que la buena voluntad ${ }^{27}$. Por eso es necesario transitar de la lógica de la acción individual a la de la acción colectiva, es decir, «moralizar» las instituciones y las organizaciones, de suerte que las consecuencias sean beneficiosas ${ }^{28}$.

Sin embargo, si nos fijamos en cuáles son los ámbitos de la ética aplicada, nos percataremos - a mi juicio- de que en todos ellos es preciso contar con instituciones, pero que les une algo más profundo. En efecto, tales campos serían, en principio: el sanitario (medicina y enfermería) ${ }^{29}$, la investigación biotecnológica ${ }^{30}$, la economía, la empresa ${ }^{31}$, la ecología ${ }^{32}$, los medios de comu-

${ }^{n}$ G. Lipovetsky,op. cit.

${ }^{28}$ P. Ulrich, Transformation der Ökonomischen Vemunft, Haupt, Bem, 1987; K. Homann/F, Blome-Drees, Wirtschafts und Untemehrnensethik, Vandenhoeck und Ruprecht, Gotinga, 1992.

" Diego Gracia, Fundamentos de bicética; Procedimientos de decisión en ética clínica; Introducción a la bioética, Santa $\mathrm{Fe}$ de Bogotá, El Búho, 1991; Ann Marrimer, Modelos y Teorías de Enfenneria, Barcelona, Rol, 1989; E. López Azpitarte en Ética y vida, Madrid, Paulinas, 1990; J. Gafo (comp.) Nuevas técnicas de reproducción humana, Madrid, Universidad Pontificia Comillas, 1986; Dilemas éticos de la medicina actual, Madrid, Universidad Pontiticia Comillas, 1986; Fundamentación de la bioética y manipulación genética, Madrid, Universidad Pontificia Comillas, 1988; El Sida: un reto a la sanidad, la sociedad y la ética, Madrid, Universidad Pontificia Comillas, 1989; La eutanasia y el ane de monir, Madrid, Universidad Pontificia Comillas, 1990; J. Gafo, Diez palabras clave en bioética, Estella, VD, 1993; Ética y Legislación en Enfermeria, Madrid, Universitas, 1994; T. L. Beauchamp, L. B. McCullough, Etica médica, Labor, Barcelona, 1987; M. Françoise Colliêre, Promover la vida, Madrid, Interamericana, MacGraw-Hill, 1993.

"José Sanmartín, Los nuevos redentores, Barcelona, Antrhopos, 1987; «El desafío de la Genética», en Tendencias científicas y sociales, núm. 19 (1990), 8 y 9; Diego Gracia, «Problemas filosóficos de la ingeniería genética», en AAVV, Manipulación genética y moral, Madrid, Fundación Universitaria CEU, 1988, 57-120; «The Status of genetic material and genctic information: the spanish situation", en H. ten Have, J. V. M. Welie, J. I. de Witte, Property and Identity on the Human Genome, Dordrecht, Kluwer Publ., en prensa; «Ethical and Social Aspects of the Human Genome Analysis», en H. Haker, K. Stiegleder, D. Mith, Ethics of Human Genome Analysis, Stuttgart, en prensa; Juan Ramón Lacadena, «El Proyecto "Genoma Humano"», en Razón y Fe, enero (1989), 43-55; AAVV, El Proyecto dal Genoma Humano, Valencia, Generalitat Valenciana, Monografies del Consell Valencià de Cultura, 1990.

Para estas cuestiones ver también la Revista de Derecho y Genoma Humano, Universidad de Deusto, Bilbao.

3: O. Gélinier, Ética de los negocios, Madrid, Espasa-Calpe, 1991; M. T. Brown, La ética en la empresa, Barcelona, Paidós, 1992; Rafael Termes, Antropologia del Capitalismo, Barcelona, Plaza 
nicación ${ }^{33}$, las organizaciones e instituciones sociales y las actividades profesionales y oficios ${ }^{34}$. En todos estos casos la raíz más profunda es que se trata de actividades sociales. Y estoy de acuerdo con Benjamin Barber cuando afirma, refiriéndose en su caso a la política, que conviene no tomar como objeto de reflexión inmediatamente las instituciones políticas; porque entonces se olvida que las instituciones son cristalizaciones de la acción humana, realizada por sujetos humanos. Es, pues, más radical examinar las actividades sociales, realizadas por sujetos humanos: la vita activa ${ }^{35}$. Ahora bien, ¿cuál es la estructura moral de una actividad social?

A mi juicio, para desarrollar una actividad moralmente en una sociedad moderna es preciso atender al menos a cinco puntos de referencia: 1) las metas sociales por las que cobra su sentido; 2) los mecanismos adecuados para alcanzarlas en una sociedad moderna; 3) el marco jurídico-politico correspondiente a la sociedad en cuestión, expresado en la constitución y en la legislación complementaria vigente; 4) las exigencias de la moral civica alcanzada por esa sociedad, y 5) las exigencias de una moral crítica planteadas por el principio de la ética discursiva ${ }^{36}$. Comentaré brevemente estos puntos.

2.1. En principio, para analizar qué sea una actividad social voy a servirme de un modelo aristotélico, concretamente, del concepto de «práctica» tal como MacIntyre lo reconstruye en Tras la Virtud. Práctica es una actividad cooperativa, que cobra su sentido, su racionalidad específica, de perseguir determinados bienes internos, lo cual exige el desarrollo de determinados hábitos por parte de quienes participan en ella. Esos hábitos recibirán el nombre de «virtudes» precisamente porque son los que nos permiten alcanzar el bien.

Trasladando esta caracterización a las actividades sociales, podríamos decir que el bien interno de la sanidad es el bien del paciente; el de la empresa, la satisfacción de necesidades humanas con calidad; el de la política, el bien

y Janés, 1992; Antonio Argandoña, Ética de la empresa, Madrid, Instituto de Estudios Económicos, 1994; Adela Cortina/Jesús Conill/Agustín Domingo/Domingo García Marzá, Ética de la empresa, Madrid, Trotta, 1994; José Luis Fernández, Ética para empresariox y directivos, Madrid, ESIC, 1994; Santiago García Echevarria, Introducción a la economía de la empresa, Madrid, Diaz de Santos, 1994; Jesús de Garay, El juego. Una ética para el mercado, Madrid, Diaz de Santos, 1994; Eugenio M. Recio/Josep M. Lotano (eds.), Persona y empresa, Barcelona, Hispano Europea, 1994.

${ }^{32}$ Karl-Otto, Diskars und Vertntwortung, Suhtkamp, 1988; Agustín Domingo, Ecologia y Solidaridad, Madrid, Sal Terre, 1991; Hans Jonas, El principio responsabilidad, Madrid, Círculo de Lectores, 1994; Nicolás Martín Sosa, Eitca ecológica, Madrid, 1990.

33 Enrique Bonete (coord.), Eticas de la Información y Deontologias del Periodismo, Madrid, Tecnos, 1995.

34 José Luis Fernández/Augusto Hortal, Etica de las profesiones, Madrid, Universidad Pontificia Comillas, 1994.

${ }^{35}$ B. Barber, Strong Democracy, University of California Press, 1984, pp. 120 y ss.

* Adela Cortina/Jesús Conill/Agustín Domingo/Domingo García Marzá, Ética de la empresa, cap. 1 . 
común de los ciudadanos; el de la docencia, la transmisión de la cultura y la formación de personas críticas; el de las biotecnologías, la investigación en pro de una humanidad más libre y feliz. Quien ingresa en una de estas actividades no puede proponerse una meta cualquiera, sino que ya le viene dada y es la que presta a su acción sentido y legitimidad social.

Con lo cual dentro de ese ámbito «deliberamos sobre los medios», como afirma Aristóteles, no sobre los fines o bienes últimos, porque éstos ya vienen dados. Y nuestra tarea consiste en dilucidar qué virtudes concretas es preciso asumir para alcanzar esos fines. Precisamente por eso en las distintas actividades humanas se introduce de nuevo la noción de «excelencia», porque no todos los que cooperan para alcanzar los bienes internos tienen la misma predisposición, el mismo grado de virtud. La virtud es graduable, y un minimo sentido de la justicia nos exige reconocer que en cada actividad unas personas son más virtuosas que otras. Esas personas son las más capacitadas para encarnar los valores de esa actividad que nos permiten alcanzar sus bienes internos. ${ }^{37}$

Las distintas actividades se caracterizan, pues, por los bienes que sólo a través de ellas se consiguen, por los valores que en la persecución de esos fines se descubren y por las virtudes cuyo cultivo exigen. Las distintas éticas aplicadas tienen por tarea, a mi juicio, averiguar qué virtudes y valores permiten alcanzar en cada caso los bienes internos. Pero teniendo en cuenta también los factores a que hemos aludido y vamos a comentar.

2.2. Para alcanzar los bienes internos de cada actividad y éste es el segundo punto de referencia al que hemos aludido es preciso contar con los mecanismos especificos de esa sociedad; en nuestro caso, con los mecanismos propios de sociedades modernas. Y aquí cntra en juego frecuentemente la necesidad de recurrir a estrategias, como exige una ética de la responsabilidad.

Por ejemplo, la actividad empresarial, dentro del contexto económico, persigue un bien interno, la satisfacción de necesidades humanas, aunque para alcanzarlo ha de contar con mecanismos, como son cl mercado, la competencia y la búsqueda del beneficio, y realizar valores peculiares, como la búsqueda de calidad, la habilidad para hacer uso de los recursos, muy especialmente los recursos humanos, etc. Ciertamente, el hecho de que para alcanzar su tïn tenga que recurrir a medios como la búsqueda del beneficio o la competitividad, despierta la sospecha de que es una actividad intrínsecamente inmoral. Sin embargo, no es así: se trata más bien de que el bien por el que cobra su sentido y legitimidad social no puede alcanzarse en una sociedad moderna si no es a través de esos mecanismos ${ }^{38}$. Otra cosa es que el medio se convierta en fin: en tal caso la actividad es inmoral, o más bien, está «desmoralizada».

37 A. MacIntyre, After Virtue, London, Duckworth, 1985, 2.a ed., cap. 14 (trad. cast. Barcelona, Crítica, 1987).

" A. Cortina/J. Conill/A. Domingo/D. García Marzá, Etica de la Empresa. 
2.3. Por otra parte, la legitimidad de cualquier actividad social exige atenerse a la legislación vigente, que marca las reglas de juego de cuantas instituciones y actividades tienen metas y efectos sociales y precisan, por tanto, legitimación. En una sociedad democrática debe atenerse al marco constitucional y a la legislación complementaria vigente.

Sin embargo, cumplir la legislación jurídico-política no basta, porque la legalidad no agota la moralidad. Y no sólo porque el marco legal puede adolecer de lagunas e insuficiencias, sino por dos razones, al menos: porque una constitución democrática es dinámica y tiene que ser reinterpretada históricamente, y porque el ámbito de lo que ha de hacerse no estará nunca totalmente juridificado ni es conveniente que lo esté. ¿Cuáles son entonces las instancias morales a las que debemos atender?

2.4. La primera de ellas es la conciencia moral civica alcanzada en una sociedad, es decir, su ética civil ${ }^{39}$.

Entiendo por «ética civil» el conjunto de valores que los ciudadanos de una sociedad pluralista ya comparten, sean cuales fueren sus concepciones de vida buena. El hecho de que ya los compartan les permite ir construyendo juntos buena parte de su vida en común ${ }^{40}$.

Por ejemplo, a la altura de nuestro tiempo una empresa está obligada a respetar los derechos de sus miembros y los de los consumidores y proveedores, y no puede atropellarlos aduciendo que su meta consiste en lograr un beneficio económico, expresado en la cuenta de resultados. Ciertamente, para satisfacer con calidad necesidades humanas (que es su meta) ha de obtener beneficio cconómico, pero no puede hacerlo a costa de los derechos de los empleados, los consumidores o los proveedores, ni el beneficio de los miembros de la empresa puede pasar por delante de los derechos de los consumidores.

Para obtener legitimidad social una actividad ha de lograr a la vez producir los bienes que de ella se esperan y respetar los derechos reconocidos por esa sociedad y los valores que tal sociedad ya comparte. De ahí que se produzca una interacción entre los valores que surgen de la actividad correspondiente y los de la sociedad, entre la ética de esa actividad y la ética civil, sin que sea posible prescindir de ninguno de los dos polos sin quedar deslegitimada.

Sin embargo, no basta con este nivel de moralidad, porque a menudo intereses espúreos pueden ir generando una especie de moralidad difusa, que hace que sean condenados por inmorales precisamente aquellos que más hacen por la justicia y por los derechos de los hombres. Tenemos en esto una larguísima historia de ejemplos. Por eso, para tomar decisiones justas es preciso, como hemos dicho, atender al derecho vigente, a las convicciones morales imperantes, pero además averiguar qué valores y derechos han de ser racionalmente res-

\footnotetext{
${ }^{19}$ Ibid., cap. 3.

4: Adela Cortina, Etica de la Sociedad Civil, Madrid, Anaya/Alauda, 1994.
} 
petados. Esta indagación nos lleva a una moral crítica, que tiene que proporcionarnos algún procedimiento para decidir cuáles son esos valores y derechos.

2.5. El hecho de que estemos hablando de sociedades modernas con democracia liberal significa que se trata de sociedades cuya conciencia moral ha accedido al nivel postconvencional, $\mathrm{cn}$ el sentido de la teoría de la evolución social de Habermas y Apel, que reconstruye a nivel filogenético la teoría del desarrollo moral de Kohiberg ${ }^{41}$. Esto significa, como hemos comentado extensamente, que cualquier actividad o institución que pretenda ser legítima ha de reconocer que los afecttados por las normas de ese ámbito son interlocutores válidos. Y esto exige considerar que tales normas serán justas únicamente si pudieran ser aceptadas por todos ellos tras un diálogo racional. Por lo tanto, obliga a tratar a los afectados como seres dotados de un conjunto de derechos, que en cada campo recibirán una especial modulación ${ }^{42}$.

\section{Proceso de toma de decisiones en los casos concretos}

Hasta ahora hemos estado tratando del marco propio de una ética aplicada, que trata de orientar la toma de decisión en los casos concretos. Estas decisiones han de ser tomadas por los afectados, que pueden contar, por supuesto, con el asesoramiento de expertos en el ámbito ético correspondiente (comités éticos hospitalarios, consulting ético de empresas, etc.) y con códigos éticos elaborados ad hoc ${ }^{43}$. Ahora bien, en la toma concreta de decisiones no basta con el marco deontológico ( kantiano») que considera a cualquier afectado como interlocutor válido, ni tampoco con el de una ética de las actividades sociales (marco «aristótelico»), porque los argumentos que se aporten al diálogo procederán de distintas tradiciones éticas.

Estos argumentos han de tener en cuenta: la actividad de la que nos ocupamos (médica, económica, ecológica) y la meta por la que esa actividad cobra su sentido; los valores, principios y actitudes que es menester desarrollar para alcanzar la meta propia, y que surgen de la modulación del principio dialógico en esa actividad concreta; los datos de la situación, que deben ser descritos y comprendidos del modo más completo posible; y las consecuencias de las distintas alternativas, que pueden valorarse desde diversos criterios, entre cllos, el utilitarista. El momento consecuencialista es, pues, imprescindible, pero siempre dentro del marco de justicia exigido por la ética dialógica.

"Adela Cortina, Ética de la Sociedad Civil,; sobre todo cap. 7.

${ }^{42}$ Puesto que resulta imposible aquí exponer y justificar esos derechos, remito a Jos lugares en que he realizado esa tarea: Ética sin moral, cap. 8; Ética aplicada y democracia radical, parte III; A. Cortina/J. Conill/A. Domingo/D. García Marzá, Ética de la empresa.

* A. Cortina/I. Conill/A. Domingo/D. García Marzá, Ética de la entpresa; sobre todo cap. 6; José Luis Fernández/Augusto Hortal (eds.), Etica de las Profesiones. 


\section{Conclusión}

A partir de lo dicho podríamos extraer un breve resumen sobre cuál debería ser la articulación de una ética aplicada en el siguiente sentido. Para diseñar la ética aplicada de cada actividad sería necesario recorrer los siguientes pasos:

1) Determinar claramente el fin especifico, el bien interno por el que cobra su scntido y lcgitimidad social.

2) Averiguar cuáles son los medios adecuados para producir ese bien en una sociedad moderna.

3) Indagar qué virtudes y valores es preciso incorporar para alcanzar el bien interno.

4) Descubrir cuáles son los valores de la moral cívica de la sociedad en la que se inscribe y qué derechos reconoce esa sociedad a las personas.

5) Averiguar qué valores de justicia exige realizar en ese ámbito el principio de la ética del discurso, propio de una moral crítica universal, que permite poner en cuestión normas vigentes.

6) Dejar las tomas de decisión en manos de los afectados que, con la ayuda de instrumentos de asesoría, ponderarán las consecuencias sirviéndose de criterios tomados de distintas tradiciones éticas. 